\title{
LOS MUERTOS DE LA PLAZA MONTT. IMAGINARIOS A PARTIR DE LA MASACRE OBRERA DEL 21 DE DICIEMBRE DE 1907 EN EL PUERTO DE IQUIQUE-CHILE
}

\author{
THE DEAD OF MONTT SQUARE. THEY ARE IMAGINARY FOLLOWING THE \\ WORKFORCE MASSACRE OF 21ST MAY 1907 IN THE HARBOR OF IQUIQUE
}

\author{
Sergio González Pizarro*
}

\begin{abstract}
La sociedad pampina ubicada en el desierto de Atacama -durante el desarrollo del ciclo de expansión del salitre- vivió en diversos momentos situaciones límites, donde sus habitantes enfrentaron la posibilidad de la muerte, como fueron los casos de algunas huelgas transformadas en masacres obreras. Aquí se analiza la conocida como "Santa María de Iquique", acontecida el 21 de diciembre de 1907 y la persistencia de su memoria. Se analizan los imaginarios que surgieron a partir de dicha masacre obrera: el rostro de muerte, la magnitud de la tragedia, el destino de los muertos (el cementerio, la fosa común y el mausoleo) y su trascendencia.
\end{abstract}

Palabras claves: Memoria, masacre obrera, rostro de la muerte, trascendencia, cementerio.

The society of the Chilean pampas located in the Atacama Desert Atacama-during the development of the nitrate expansion cyclelived limiting situations in different moments, where its inhabitants faced the possibility to die, such as in some strikes becoming labour massacres. It is analysed here the one that is known as "Santa María de Iquique", that happened on 21 December, 1907, and the persistence of its memory. Imaginary that arose from that labour massacre is analysed: the face of death, the importance of the tragedy, the destination of the dead people (the cemetery, the mass grave and the mausoleum) and their significance.

Key words: Memory, labour massacre, faces of death, significance, cemetery.

\section{Introducción}

Este 2017 se conmemoran 110 años de los sucesos acontecidos un 21 de diciembre de 1907 en la escuela Santa María de Iquique, que han sido analizados desde diversos puntos de vista y enfoques disciplinarios, como también haber inspirado diversas expresiones de arte. Sin embargo, era necesaria también una reflexión acerca de los imaginarios que surgieron a partir de la muerte de esas personas que, más allá de haber estado o no conscientes de su destino, trascendieron a su tiempo y su espacio. Por aquello, no es propósito de este artículo la indagación de responsabilidades o de detalles historiográficos desconocidos, sino plantearse otras preguntas y girar hacia otros ángulos, como por ejemplo, preguntarse por el supuesto cementerio $\mathrm{N}^{\circ} 2$, donde se ubicaría la fosa común, o enfocarse en el rostro de los fallecidos, recurriendo a la perspectiva filosófica de Levinas.

Dicho lo anterior, es menester señalar que la huelga y posterior masacre obrera, acontecida en la ciudad-puerto de Iquique en el norte de Chile, el 21 de diciembre de 1907, durante el auge de la economía salitrera, se ha transformado en la más importante del país desde un punto de vista historiográfico (Devés 1988; Fernández 1988; Pizarro 1986; Bravo 2007; Artaza 2006; González 2007) y cultural. En esta última dimensión, algunas obras han alcanzado gran relevancia social, como la "Cantata de Santa María de Iquique" de Luis Advis y la novela "Hijo del Salitre" de Volodia Teitelboim. Más reciente es la novela "Santa María de las flores negras" de Hernán Rivera Letelier, que ha tenido también gran éxito de venta. También inspiró una obra de teatro, del dramaturgo chileno radicado en Lima, Sergio Arrau: "Santa María del Salitre", editada y estrenada en Iquique en 1989. El poema del obrero pampino Francisco Pezoa, titulado "Canto de venganza" y publicado el 18 de abril de 1908 en el diario El Pueblo Obrero de Iquique, se hizo muy popular bajo el nombre de "Canto a la pampa" con música del vals "Ausencia". Además, resulta considerable que los periodistas Osvaldo López y Nicanor Polo, del periódico El Pueblo de Iquique, hayan publicado una novela titulada Tarapacá bajo

\footnotetext{
* Universidad Arturo Prat. Iquique, Chile. Instituto de Estudios Internacionales. Correo electrónico: sergiogpizarro@ gmail.com
} 
el seudónimo de Juanito Zolá, en 1903, premonitoria de la huelga y masacre de 1907.

Es admisible destacar que -esta no fue la única huelga que tuvo por resultado una masacre obrera en la historia del salitre- se ha transformado en un símbolo de todo lo que fue el movimiento social de ese periodo enmarcado entre 1880 y 1920. La imagen de la muerte de los pampinos y de la notoria injusticia de su tragedia, que quedó registrada en la memoria de la población regional y nacional, es la que explica esa persistencia cultural de este acontecimiento.

Se ha organizado este trabajo en torno a cuatro imaginarios que surgieron a partir de este acontecimiento:

1. El primero se refiere a la imagen del pampino que quedó impregnada en la memoria de la población local, y que se ha transmitido de generación en generación respecto de quienes fueron los que bajaron desde el desierto al puerto de Iquique, para solicitarle a la autoridad la restitución del valor del peso a 18 peniques como había sido años antes, pues, la alta inflación había devaluado el tipo de cambio a menos de un tercio. Se sabía que 1907 era un año de auge de la economía del nitrato chileno, por tanto, era una demanda ajustada a las posibilidades del empresariado salitrero. Los obreros huelguistas después de ser calificados como un peligro, la memoria los transformó en mártires de una injusticia, a tal punto que para el centenario de la masacre, el ministro del Interior de la época, Belisario Velasco, pidió perdón a nombre del Estado de Chile. Por esta razón, la imagen que persigue este estudio es el rostro del pampino, siguiendo la perspectiva de Levinas.

2. El segundo dice relación con una discusión que posiblemente no logre nunca consenso: la cantidad de muertos de la Plaza Montt o de la escuela Santa María de Iquique. Desde la cifra de 140, entre muertos y heridos, informada por el general Roberto Silva Renard, hasta los 3.600 de la "Cantata de Santa María de Iquique". La importancia de esta discusión se relaciona con la cantidad de personas que bajaron desde las salitreras hacia el puerto de Iquique, la que habría generado un temor en la población local y que, supuestamente, habría justificado la represión del 21 de diciembre. También se relaciona con el temor hacia una violencia popular que se asociaba ideológicamente a los pampinos a partir de un imaginario de civilización y barbarie.

3. El tercer imaginario emerge del supuesto cementerio donde fueron trasladados los muertos de la plaza Montt, porque tal camposanto no existía en 1907 y tampoco existe en la actualidad. Aquí se hace relevante la tensión entre la persistencia del recuerdo del acontecimiento y la desaparición del lugar de memoria.

4. El cuarto imaginario se deriva del anterior, y se refiere al mausoleo que las organizaciones obreras construyeron en el Cementerio $\mathrm{N}^{\circ} 2$, lo que permite analizar la imagen de la muerte y su trascendencia que tuvo la población pampina y que todavía puede registrarse, por medio de los centros pampinos existentes hoy. Como también, permite discutir el componente cultural de origen andino en la cosmovisión de la población pampina que, no siendo contradictorio, no responde a la cultura ilustrada que la historiografía le asigna a los dirigentes de la huelga pampina de 1907.

\section{El "rostro" de los muertos de la Plaza Montt}

Los relatos de época se refieren a la posible identidad del sujeto que en esos minutos previos enfrentó al general Roberto Silva Renard y, supuestamente, le indicó su pecho para que disparara. La memoria lo recuerda como "el rucio". El general Silva Renard debió ver muchos rostros de hombres y mujeres en ese momento, pero posiblemente no estableció una relación intersubjetiva prolongada con ninguno. En cambio, los rostros de los asesinados quedaron grabados en la memoria de quienes les vieron, especialmente los bomberos, quienes tuvieron la triste tarea de trasladar a los muertos a una fosa común en un terreno adyacente al cementerio $\mathrm{N}^{\circ} 1$, que se reconocerá como el cementerio $\mathrm{N}^{\circ} 2$. Los relatos acerca de estos muertos se transmitieron de generación en generación, dejando una imagen en la población local -de todos los sectores sociales y políticos- respecto de la magnitud del crimen.

Immanuel Levinas se enfoca en el rostro para definir su fenomenología y su ética. Este autor expone: "El rostro está expuesto, amenazado, como invitándonos a un acto de violencia. Al mismo tiempo, es el rostro el que nos impide matar" (2008:72). La tentación y la imposibilidad de asesinar, para Levinas, constituyen la visión misma 
del rostro, siendo una imposibilidad más moral que real, porque igualmente los hombres matan y pueden hacerlo en momentos de paz, como ha acontecido en las masacres obreras. Para Levinas, el rostro implica una responsabilidad o fuente de obligación hacia los otros hombres. En palabras de este autor: "pienso que la responsabilidad por el otro hombre o, si lo prefiere, la epifanía del rostro humano constituye algo así como la perforación de la costra del 'ser perseverando en su ser' y cuidando de sî’” (2004:128). El señor Ángelo Frassinetti en una entrevista realizada en 1987 y registrada en el archivo de Hombres y Mujeres de la Pampa ${ }^{1}$ (González 2002), recordaba que su padre había sido bombero durante la masacre obrera del 21 de diciembre de 1907 y señala lo siguiente:

Plaza Montt se llamaba. En una parte estaban cerradas esas calles, en unas partes las cerraban. Cuando sintió el chancaqueo, (el) baleo, entonces dice mi papá: Es cosa rápida. Mire la iniciativa de mi padre, se puso la chaqueta de la bomba $\mathrm{N}^{\circ} 4$ y corrió por la calle Latorre (...) en la calle Vivar al subir por Latorre la sangre llegaba corriendo. Qué ocurre, la sangre corre como río. Y dice mi papá, que cuenta detalles tan precisos que son difíciles saberlos por otras personas, y dice mi papá que cuando fue allá todavía había uno vivo. En ese tiempo había carretas azulinas. Entonces llegaron las carretas basureras. Lo pescó y lo echó adentro de la carreta basurera. Lo revisaban por si tenía algo. Así era la orden (...) Dice que en ese tiempo usaba la gente bigotes de percha, unos bigotes tremendos. No como ahora que no usan bigotes. Dice que nunca lo podrá olvidar, lo tenía en la mente, este gallo estaba comiendo algo cuando murió, tenía un pan en la boca pescado con rabia y con tremendo bigote dice. Cuando los sacaban tenían que verle, otros los echaban a las carretas. Montones de muertos en las carretas. Mi papá todos los días se acordaba cuando veía gente con bigote. Ese hombre que lo vio con pan en la boca, con una rabia terrible.

El rostro de ese hombre quedó retenido en la memoria de ese bombero que cumplía la tarea voluntaria de despejar la escuela Santa María de
Iquique de muertos y heridos. Vio en ese rostro la rabia expresada en un pan, el motivo de la huelga, en el preciso instante en que la muerte marcó el tiempo de ese obrero de la pampa. Para Levinas el rostro habla. "Habla en la medida en que es él el que hace posible y comienza todo discurso" (2008:73).

La orden del general Roberto Silva Renard de disparar asesinó a cientos de personas pero no logró evitar que ese rostro -como el de otros-quedara en la memoria como un imposible moral.

Por otro lado, la señora Prosperina Marangunic nos cuenta que su padre fue fundador de la bomba Dalmacia $\mathrm{N}^{\circ} 5$ y también cuenta que fueron los bomberos los que sacaron a los muertos de la escuela Santa María, dando cuenta del rol clave en la construcción de los imaginarios colectivos relacionados a la masacre y del contexto de violencia y miedo de aquel día:

Todos los que fueran bomberos, otra persona particular no podía entrar ahí (a sacar a los muertos). Dice mi papá que llegaron ahí. Dice que llegó el general Silva Renard, pedían los 18 peniques, quién sabe qué será eso de los 18 peniques, todavía no me he acordado (...) La gente en Iquique no abre ni las puertas, nada. Y las personas arrancando desesperadas no hallaban para dónde irse, los hombres sobre todo. Se fueron al Hipódromo que era ahora donde juegan fútbol. A esos los llevaron al hipódromo. Ahí les dieron de comer hasta que pudieran irse otra vez a las oficinas. También teníamos un vecino, la señora se había casado de 16 años y él de 21. Llega el entusiasmo, compañeros vamos, vamos a reclamar los peniques. Se puso su ropa, su pantalón blanco, su colisa en esa época se usaba colisas y su chaleco y salió. No vio más a la señora. Nada más que en la noche estaba durmiendo sola cuando le golpean la puerta, al ir a ver qué es lo que pasaba, era su marido. Estaba irreconocible dicen. El pantalón blanco era pura sangre, lo desconoció y se desmayó. Entonces le dijo te vine a avisar que ya mataron a todos, yo me escape tirándome arriba de otro muerto, le dijo. ¡El coraje! (...) Asustado venía, creía que lo venían siguiendo (...) Fue terrible. Yo digo que si tuviéramos el conocimiento que tenemos ahora ya no 
hacen tantas cosas con los pobres, esto no se habría levantado yo creo. Cómo no iban a levantarse viendo tanta maldad, tanta picardía para defenderse de unos obreros que no sabían leer ni escribir... Con el fin de ganar plata se venían a la aventura. Había muchos bolivianos, mucha gente peruana también.

¿Qué puede separar tanto a personas que pertenecen a una misma sociedad y que están en un escenario de paz, para decidir su asesinato para resolver un conflicto laboral?, ¿es solamente la alteridad de clase? Levinas plantea que "el otro no niega pura y simplemente al Yo: la negación total, cuya tentación y tentativa es el asesinato, remite a una relación previa" (1977:215).

El general Roberto Silva Renard ya había tenido una relación previa con los obreros de la pampa, en donde se materializaba aquella alteridad de clase y la negación del otro. En 1904 le correspondió reprimir una huelga en las oficinas salitreras del cantón Toco, ubicado en la provincia de Antofagasta, al interior del puerto de Tocopilla, en una zona muy próxima a la provincia de Tarapacá, es por ello que se solicitó ayuda a las guarniciones de Iquique para sofocar este movimiento obrero. Desde Iquique partió con destino al Toco el vapor California que "condujo un escuadrón de caballería y una compañía de infantería. De Valparaíso zarpó un transporte de la Armada con una fuerza de caballería. Esos refuerzos se unían a las tropas de desembarco de los cruceros Blanco Encalada y Chacabuco, que se hallaban en Tocopilla" (Zolezzi 2002:37), el mando recayó en Silva Renard, quien logró que los obreros desistieran de su huelga, permitiéndoles a los que no deseaban seguir trabajando en esas salitreras pasajes para embarcarse hacia el sur del país. Este general dejó un destacamento militar estable en ese cantón salitrero, y que, sin duda, los obreros de la pampa eran vistos como enemigos, donde la posibilidad del asesinato era una medida posible como devenimiento de la negación total que se aproximaba.

En 1910, tres años después de la masacre de Iquique, Silva Renard fue ascendido al grado de general de división, el más alto de la carrera militar. Lo que demuestra la existencia de una institucionalidad que valoraba positivamente esta conducta en quienes tenían la responsabilidad del mando. Por tanto, enfocarse en el general Silva Renard como responsable de lo acontecido es sociológicamente erróneo. En otras palabras, la responsabilidad de los muertos de la Plaza Montt expresa una violencia estructural/institucional que trasciende a la persona $\mathrm{y}$, sobre todo, el rostro de este general.

Johan Galtung establece una distinción respecto de si hay o no un sujeto (persona) actuante. Señala que "al tipo de violencia en la que hay un actor que comete la violencia lo llamaremos violencia personal o directa, y llamaremos a la violencia en la que no hay tal actor, violencia estructural o indirecta" (1995:350). Este autor establece también una diferencia entre la dicotomía individual/institucional respecto de la personal/estructural, porque "la persona puede actuar a veces en beneficio de grupos, mientras que lo individual puede interpretarse como opuesto al grupo". Y por otra parte, "hemos preferido lo estructural porque a menudo es algo de naturaleza más abstracta y no algo que pueda atribuirse a una institución en especial" (1995: 350). Si bien aquí estamos frente a una violencia física, con actores identificados, y que representan instituciones definidas, la responsabilidad es estructural, la estructura que definen las alteridades de clase que permiten el imposible moral del asesinato, y en este caso, de la masacre de las estructuras por las agencias.

Es posible mencionar que los rostros de los muertos de la Plaza Montt no expresaban a individuos en específico, sino a toda una sociedad que habitó el desierto y que, como lo hizo en otras ocasiones, demandó a las autoridades, en quienes confiaban, medidas bien concretas, no solo referidas al salario, sino a la seguridad laboral, a la educación pública, las fichas-salarios, la venta de alcoholes, etc. Demandas que con los años han sido consideradas en las leyes sociales del país.

Una carreta llevó el cuerpo del huelguista cuyo rostro impresionó al padre de Ángelo Frassinetti, quien había llegado desde la pampa salitrera lleno de vida días antes, en dirección del supuestamente cementerio $\mathrm{N}^{\mathrm{o}} 2$ de Iquique. Allí se unió en un abrazo eterno a otros cientos de cuerpos en una fosa común.

La historiografía recoge la información que los muertos de la Plaza Montt fueron llevados al cementerio $\mathrm{N}^{\circ} 2$ de Iquique, pero en realidad fueron llevados a un terreno baldío a un costado del cementerio $\mathrm{N}^{\circ} 1$, que con el tiempo se transformaría en un camposanto. Los obreros de la pampa no pudieron ingresar al mismo cementerio donde estaban enterrados los empresarios del salitre y sus mausoleos de mármol perpetuando la alteridad. 
Porque, claro, ¿cómo podrían los rostros de la pampa y del salitre inmortalizarse con sus propios asesinos? Como dice Levinas, toda masacre remite a una relación anterior. Relaciones que no solo son hechos concretos entre militares y obreros, entre dueños de oficinas y obreros, entre gobernantes y obreros, en el transcurso de sus vidas en particular, sino que es su relación estamental o de clase que los define. Como se señalaba anteriormente, lo estructural de una sociedad es lo que divide a los sujetos de esa sociedad. El obrero del caliche, era el pobre como manifestaba Prosperina Marangunic, ese era su rostro que se inmortaliza, pero el obrero de la masacre de 1907 no solo era pobre, sino que era un pobre con rabia como lo expresaba el recuerdo de la familia Frassinetti, era un pobre valiente, que en sus últimos días dejaron la vida por sus derechos. Objetivo que fue mermado por la violencia generada por el poder único de la legalidad coercitiva, pero que no impidió que la memoria histórica recuerde sus rostros pampinos, de esfuerzo y compromiso con una causa justa que hoy se hace presente en cada lucha social.

\section{La cifra de los muertos de la Plaza Montt y la "violencia popular"}

Una de las incógnitas que ha rodeado la masacre del 21 de diciembre de 1907 ha sido el número de muertos. Desde unos cientos hasta miles son los cómputos. El relato más sereno ha sido del médico Nicolás Palacios, testigo del suceso y cronista del mismo. Nos dice que "tendidos en el campo antes de concluir el acarreo, halló un practicante militar 200 cadáveres. Una vez después de la matanza, un farmacéutico que atendía heridos, contó 117 . El doctor Gómez halló 98, y el capellán de ejército don V.M. Montero, 91" (Bravo Elizondo 2007:73). 40 fallecidos fueron llevados directamente al cementerio según el cálculo de Palacios, a pesar que el practicante señaló un total de 200. Después nos dice que la estadística del Hospital registra 95 cadáveres hasta ese recinto, pero de los heridos murieron 29 hombres y 1 mujer. Muchos murieron en casas particulares donde escaparon heridos, Palacios nos menciona a un señor Queirolo que "halló al anochecer de ese día, 5 muertos entre una veintena de heridos en el conventillo $\mathrm{N}^{\circ} 198$ de la calle Barros Arana" (Bravo Elizondo 2007:73). El cómputo total al que llega este autor es de 585 bajas huelguistas.
El periódico El Proletario de la ciudad de Antofagasta, del 29 de diciembre de 1907, señala que fueron 494 muertos y 549 heridos, según reportes de informantes informales, que rebatían la versión oficial de Silva Renard que establecía 140 entre muertos y heridos.

Estas cifras son equilibradas y reflejan lo que pudo ser el resultado de la masacre del sábado 21 de diciembre, debiendo agregarse también los heridos que fallecieron después, una vez llegados por sus medios a los campamentos salitreros.

El escritor antofagastino (nacido en Taltal) Mario Bahamonde hace una certera reflexión acerca de este tema:

La muerte no es una estadística: es un hecho personal y privado que se convierte en público cuando la maldad humana desata sus huracanes. Y entonces da lo mismo que sean cien o mil, porque más allá del dolor, solo pesa la injusticia, la implacable inconsciencia, especialmente si se trata de amparar un sistema en el que la carne humana es un medio para sustentar la riqueza (1973:93).

Dando cuenta de lo que "pesa" esta masacre, es decir, lo que inunda el recuerdo y la memoria histórica en los imaginarios nortinos y nacionales: la injusticia por la avaricia. La cantidad de muertos, llevó a la especulación de imágenes muy fuertes, como la existencia de pilas de muertos, o que la sangre corría como río por la calle Latorre hacia el mar. Basta, como ejemplo, el testimonio del diputado de la República, perteneciente al Partido Demócrata, Malaquías Concha, ante el Congreso Nacional:

Sobre diez mil obreros inermes se disparó con ametralladoras, no por el espacio de treinta segundos, como dice el parte, sino que esta espantosa carnicería duró, por lo menos, tres minutos. ¡Y no se creyó que esa inhumana carnicería era bastante. La fuerza pública escaló la pirámide de cadáveres que obstruía el paso en el zaguán de la casa, y, penetrando al interior, cargó sobre los que habían podido escapar y descargaban sus armas sobre esa multitud de hombres, mujeres y niños que en su angustia y desesperación inmensa, en 
medio de las lágrimas y de los gritos de piedad, levantaban, sin hallar compasión, sus pañuelos blancos o los jirones de sus camisas ensangrentadas pidiendo que no se continuara fusilándolos tan cruel e inhumanamente, pidiendo misericordia! (Bravo-Elizondo 2007:192).

El censo de Iquique ese año alcanzó la cifra de 40.171 individuos, y el cálculo de las personas que bajaron desde las salitreras a este puerto supera las 10.000, generando un entendible temor entre la población local, la que se utilizó como justificación de la masacre, a saber, el carácter violento de los huelguistas. Sin embargo, el comportamiento ordenado de los huelguistas generó una notoria simpatía, que se transformaría en crítica hacia las autoridades después de la represión que implicó la muerte de hombres, mujeres y niños, en la Plaza Montt y la escuela pública Domingo Santa María. ¿Los obreros contribuyeron a esa imagen de violencia?, posiblemente sí, especialmente desde quienes tenían alguna ideología que la justificara. Tal como registra el periódico El trabajo de Tocopilla, el 27 de diciembre de 1907, con una nota hacia el gobernador Víctor Gutiérrez señalando:

Los mineros de la pampa, para cargar un tiro en sus calicheras, colocan algunos sacos de pólvora en la parte inferior, y lo mechan con cartuchos de dinamitas que llaman callos (...) Por lo regular, cada barretero emplea al día cinco a diez cartuchos de dinamita: la bastante para hacer volar algunas carretadas de caliche; pero lo bastante también para hacer volar unos edificios con administrador, pulpero, correctores, boletero y cuanto gringo haya en los alrededores.

Los periódicos de la ciudad en un primer momento descalificaron a los pampinos tratándolos como sediciosos (El Tarapacá, 1907). Bajo este principio, las autoridades locales y nacionales actuaron: exigieron primero la obediencia, que implicara el retorno inmediato a las salitreras, para restituir un orden supuestamente alterado por la mera presencia de los pampinos, cumplido esa orden se podría discutir el pliego de peticiones. La desobediencia tuvo por resultado la represión por la fuerza. Al parecer el valor del "orden" estuvo por sobre la vida de los obreros de la pampa.
El temor por la violencia de los pampinos estuvo basada esencialmente en el desconocimiento del "otro" o en la construcción de otro, donde la dicotomía de civilización y barbarie no estuvo ausente, especialmente cuando al pampino se le asoció con el indígena (Figueroa, 2011). Aunque también la violencia se relacionó, claramente, con la "violencia popular".

La imagen del pampino de un sujeto peligroso ya venía de antes, para Julio Pinto "cualquier tipo de violencia popular tendía a ser percibida por los sectores dominantes como un acto de indisciplina social (...) de todas maneras, perturbaban un orden que para los representantes de la autoridad era preciso mantener" (1998:90).

A la "violencia popular" que define Pinto es posible sumarle otra de carácter más estructural, donde la responsabilidad de un acontecimiento como una masacre obrera, no depende de las decisiones de una persona, sino que responde a una responsabilidad institucional. Algunos historiadores se enfocaron, por ejemplo, en el general Silva Renard como el responsable de la masacre (Zolezzi 2002) y también obreros más ideologizados. Esa perspectiva elude la responsabilidad del Estado-Nación y de la propia sociedad de clase.

La protesta obrera que llevó a la huelga ese año no responde a la corriente política e intelectual que se inicia pocos años después en el marco del centenario de la República, acontecido en 1910. Al contrario, con este suceso se cierra el periodo anterior, propio de organizaciones internacionalistas, como mancomunales, mutuales, sociedades de resistencia, organizaciones anarquistas, entre otras, para dar paso a las de carácter nacional, como fue la Federación Obrera de Chile, fundada en 1909, y el surgimiento de los primeros partidos políticos obreros, como el POS (Partido Obrero Socialista), fundado en Iquique y en la pampa salitrera de Tarapacá en 1912.

En definitiva, el imaginario que se constituye a base del aspecto más bien cuantitativo de la masacre, es oscilante entre cifras de diverso tipo, así como se señaló anteriormente, pero el contenido subjetivo, y fundamentalmente intersubjetivo que transciende desde los números aportados, es lo que se transporta por más de cien años, una carga emotiva en cada sujeto, no solamente ligados a la pampa, Iquique, o al norte de Chile, sino que por medio del discurso social, la historiografía, la educación curricular, y esencialmente el imaginario popular 
que simboliza aquella masacre, se ha masificado a niveles internacionales. Se han articulado sentimientos, sensaciones, pensamientos y acciones en relación con un hecho en particular. Aquello refleja una característica que nace desde el inicio de la organización obrera al interior de la ciudad de Iquique en 1907: el carácter sumamente colectivo de este recuerdo, de este imaginario que se construye basada en las acciones propias de sus actores, acciones mancomunadas, acciones comunitarias y solidarias que consolidaban las relaciones con "el otro". En suma, no es solo el número de muertos lo que define este tópico, sino que el número de relaciones conectadas entre sí por una lucha social, por un compromiso con la vida más digna, las que fueron despojadas de sus vidas naturales, pero no de su nexo, nexo inmortalizado por el imaginario, por la memoria colectiva, que hoy y ayer une más que separa, al igual como se unieron los miles de obreros huelguistas en 1907.

\section{Los camposantos de Iquique en 1907}

El puerto de Iquique tiene actualmente tres cementerios, el más tradicional es el $\mathrm{N}^{\circ} 1$, donde se pueden encontrar lo grandes mausoleos de los empresarios salitreros que vivieron el auge de esta economía minera, entre el último tercio del siglo XIX y el primero del XX. Le sigue otro, $\mathrm{N}^{\circ} 3$, más modesto, levantado en el límite oriental de la ciudad a comienzos del siglo XX, caracterizado por las construcciones de cemento con gran capacidad de nichos. Y el tercero ya no lleva un número, sino un empresarial y atractivo eslogan: "Parque del Sendero". La pregunta es por el cementerio $\mathrm{N}^{\circ} 2$, ¿no existió o fue eliminado?

El plano de Iquique de Edward E. Muecke de 1907 (Figura 1) no registra al cementerio $N^{\circ} 2$ y tampoco al $\mathrm{N}^{\mathrm{o}} 3$. El cementerio $\mathrm{N}^{\circ} 3$ fue ubicado en una calle que dicho plano considera como sitio baldío, más allá de los límites de la ciudad. Las primeras tumbas registradas en este camposanto son de 1910, lo que explica su ausencia en el mencionado plano (El Tarapacá 1959). El cementerio $\mathrm{N}^{\mathrm{o}} 1$ ocupa un lugar destacado demostrando su importancia para la ciudad y próximo a su muro norte debió estar el $\mathrm{N}^{\circ}$ 2, pero no lo indica, a pesar que allí fueron enviados los obreros muertos en la más recordada masacre obrera de la historia de Chile.

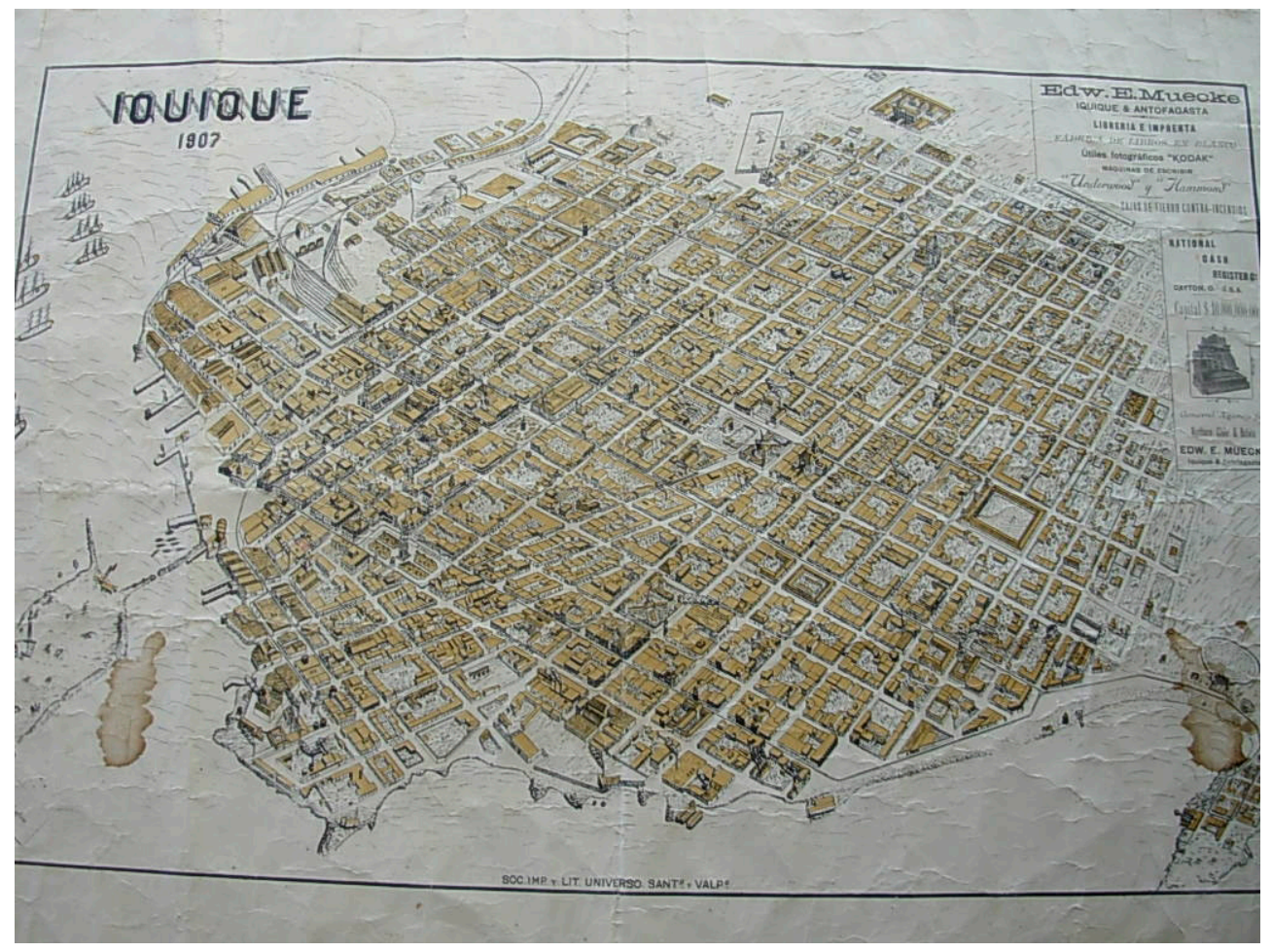

Figura 1. Plano de Iquique de Edward E. Muecke de 1907. Fuente: Archivo fotográfico del autor. 
Lo que resulta más plausible es que, al costado norte del cementerio $\mathrm{N}^{\circ} 1$ se ubicó el lazareto para los infectados de la peste bubónica de 1903 y siguientes, para posteriormente transformarse en un cementerio escasamente regulado y administrado, incluso nunca tuvo un cierre perimetral. A pesar del deterioro, por décadas la fosa común con los restos de los caídos en la Plaza Montt fue un lugar de peregrinación de las organizaciones obreras de la ciudad.

El cronista Carlos Alfaro Calderón, respecto del cementerio $\mathrm{N}^{\circ}$ 2, menciona lo siguiente: "en cuanto al cementerio $\mathrm{N}^{\circ} 2$, su clausura se debió a que su espacio es reducido y como su habilitación fue en épocas de continua propagación y mortíferas epidemias, ese espacio fue llenado en poco tiempo" (1936:354). Si bien no indica la fecha del cierre del cementerio, queda claro que fue antes de 1936.

Para un $1^{\circ}$ de mayo de 1951 , un periodista hizo un recorrido por el cementerio $\mathrm{N}^{\circ} 2$, y señaló:

\begin{abstract}
Allí todo es profanación y abandono y lo más grosero aún es que ciertas partes de este camposanto están convertidas en letrinas (...) Vamos después al monolito de los caídos en la huelga de 1907. Al año siguiente los tipógrafos iquiqueños y el partido demócrata organizaron una romería. Al borde de aquella fosa común, el tipógrafo Luis Víctor Cruz pronunció una sentida oración fúnebre en su memoria. Huesos botados a flor de tierra, calaveras, "canillas", osamentas casi enteras. Profanación y nada más que profanación $(E l$ Tarapacá 1959).
\end{abstract}

Este cementerio a comienzos de la década de 1950 habría sido clausurado, sin bien se podía visitar, no tenía agua disponible para las flores que los deudos le llevaban a los muertos. Para el $1^{\circ}$ de noviembre de 1951 las autoridades aseguraron el suministro de agua para los cementerios $\mathrm{N}^{\circ} 1$ y 3 con tambores transportados por carretas, a partir de las 7:00 horas., no así para el $\mathrm{N}^{\circ} 2$. Sin embargo, el periodismo menciona que: "En forma continuada a través de todo el día visitó el público este cementerio, naturalmente, la afluencia fue mucho menor, pero se prolongó hasta las últimas horas de la tarde" (El Tarapacá 1951).

El deterioro de este cementerio fue creciente con el tiempo. Su ubicación en el margen norte de la ciudad, al costado del cementerio $\mathrm{N}^{\mathrm{o}} 1$, fue por una parte en beneficio de su lento olvido, pero allí estaba la fosa común de los muertos de 1907 y su recuerdo era un imperativo ético para la población local y especialmente para los pampinos. Se construyó un mausoleo de madera con una estatua de un pampino (Figura 2). Símbolo necesario para todo tipo de recuerdos sociales e históricos como estos, en especial en la región de Tarapacá, que se caracteriza por simbolizar en nombres, estatuas, monolitos, o lugares específicos de las ciudades o pueblos, su historia, sus recuerdos, sus imaginarios, quedando reflejado, por ejemplo, en los patrones religiosos como la virgen del Carmen y San Lorenzo, en donde la fe, las creencias y las esperanzas más poderosas quedan cristalizadas en aquellas simbolizaciones: los pampinos muertos en 1907 no podían ser menos. La simbolización permite encuentro, permite ubicación referencial para la memoria histórica.

\section{El mausoleo de los mártires de la Plaza Montt}

¿Qué significó el modesto mausoleo de madera que marcaba la fosa común de los muertos del 21 de diciembre de 1907? En 1987 se recogió un relevante testimonio de un pampino carretero de los cantones de la zona norte de Tarapacá, Eugenio Figueroa, quien escuchó en las salitreras los relatos de su suegro, protagonista de la masacre de 1907.

Las carretas del Municipal había como 40 carretas. De las siete de la mañana hasta las seis de la tarde cargando los finados. No los llevaban al Hospital, sino que los llevaban adonde llevaban los apestados. Atrás del Cementerio viejo había un lazareto. Ahí las llevaban a reconocer su marido a las mujeres.

Eduardo Devés, posiblemente quien ha escrito el libro más completo sobre este acontecimiento, afirma que:

El entierro, el mausoleo obrero, la ceremonia son caminos importantes para penetrar en el universo cultural de las organizaciones de comienzos de siglo. Es curiosa la importancia atribuida al funeral por organizaciones que jamás hablan de la muerte sino en sentido político o militante: la muerte por una causa, la muerte del guerrero en la lucha de clases (1987:203). 


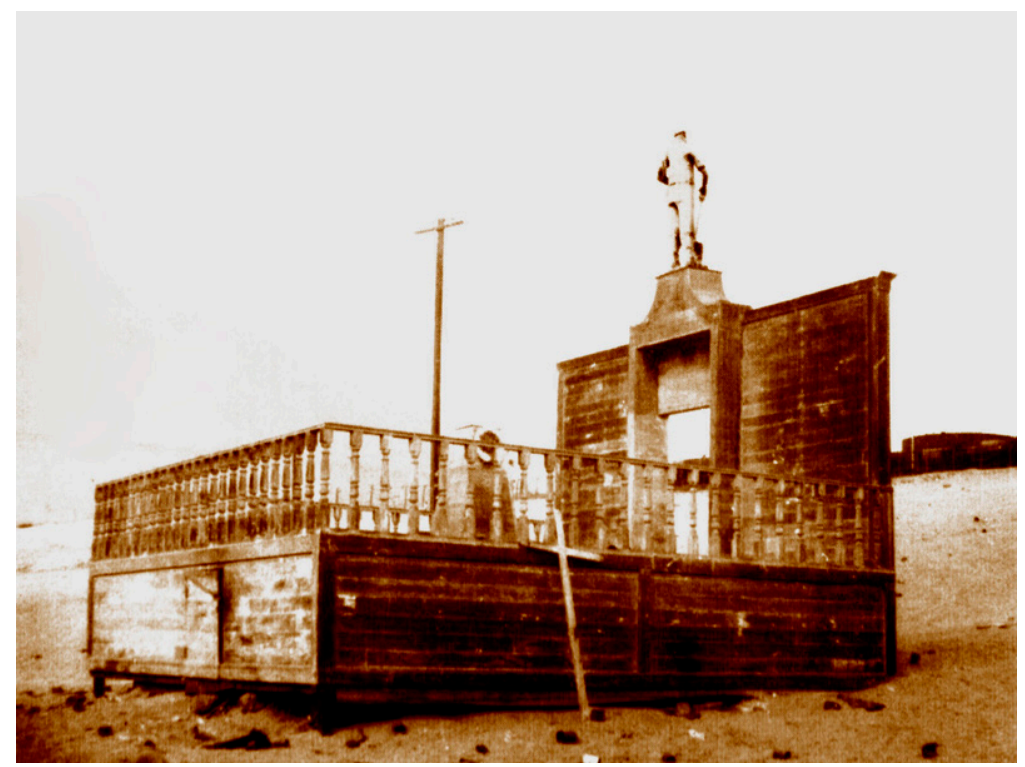

Figura 2. El Mausoleo de los Mártires de la Plaza Montt. Fuente: 1907 Santa María de Iquique. Museo regional de Iquique.

Incluso este autor se pregunta: "en esta cultura obrera oficial de tiempos del centenario ¿qué sentido tienen los mausoleos obreros?" (1987:203). Puede ser una pregunta válida para algunos mausoleos obreros, en cambio, para el que fue construido en el cementerio $\mathrm{N}^{\circ} 2$, en el lugar donde fueron lanzados los cuerpos de los asesinados responde al imaginario que los pampinos tenían de lo que era una tumba. Posiblemente, los hombres y mujeres de la pampa han tenido conciencia de trascendencia que permite el desierto al momificar naturalmente a los cuerpos. Sea una fosa común, una simple tumba o un mausoleo de madera, son lugares de memoria para los habitantes del desierto, lo que está más allá de la problemática ideológica e ilustrada de un movimiento obrero. Los dirigentes de la huelga eran obreros ilustrados algunos, anarquistas o socialistas, no todos fueron pampinos, porque en los días previos se unieron los de la pampa y el puerto en un único comité de huelga, compartiendo los cargos directivos, en cambio, la gran masa superior de diez mil personas llegó procedente de las oficinas salitreras.

Valentín Cuevas, uno de los dirigentes que fueron enjuiciados, publicó su defensa en diario El Pueblo del 28 de mayo de 1908, donde señala que: "Las inocentes víctimas de la masacre del 21, desde la fosa común claman justicia contra tantas inequidades y atropellos, sus tumbas se conmueven y esperan que su sacrificio no será estéril" (Bravo-Elizondo 2007:215). Vemos cómo este dirigente siguió creyendo e insistiendo en el carácter legítimo de la demanda obrera, esperando que la justicia emane desde el lugar sacro donde fueron sepultados los muertos de la Plaza Montt. Este sitio de memoria fue eliminado.

¿Fue la fosa común en el cementerio $\mathrm{N}^{\circ} 2$ un lugar de peregrinación? La señora Otilia Miranda recuerda que para los aniversarios de la masacre obrera se visitaba la fosa común en el cementerio $\mathrm{N}^{\circ} 2$ :

Casi nadie conversaba de eso, cuando llegaba la fecha toda la gente estaba con tristeza, iban al cementerio dos, llegaba la gente de la pampa y echaban flores a la fosa, se notaba el montón de cadáveres, estaba todo abierto ahí.

Como se puede demostrar, las organizaciones de pampinos tienen especial preocupación por llevar flores de papel a los distintos cementerios ubicados a lo largo del desierto de Atacama. Incluso, actualmente las mujeres de centros pampinos se especializan en la elaboración de flores de lata y de papel, para luego ir en el día de los difuntos a instalarlas en las tumbas de diversos cementerios de la pampa. 
Philippe Aries nos recuerda que "la tumba en el lugar del martirio es objeto de culto no ya familiar y privado, sino colectivo. Las tumbas se convierten en monumentos, los monumentos se ven obligados a convertirse en tumbas" (1999:456). Efectivamente, las tumbas de los cementerios de la pampa se han convertido en objeto de culto colectivo, donde las flores son la ofrenda. Las flores tienen un sentido dentro no solo de la cosmovisión occidental, sino también andina.

La relación entre la pampa salitrera y el santuario de la virgen del Carmen de La Tirana, cuyas raíces andinas han sido muy estudiadas (van Kessel 1987; Núñez 2004; González 2006), demostrando que durante el ciclo del salitre hubo una resignificación de esta fiesta. A pesar de ello, la virgen del Carmen siempre se asocia a la pachamama (van Kessel 1987). Curiosamente los cantos de los peregrinos suelen referirse a la virgen como "bella flor", cuando es un santuario ubicado en pleno desierto. No es extraño que en las oficinas salitreras se hayan fabricado flores de lata, de papel e incluso de loza.

El cementerio $\mathrm{N}^{\circ} 2$ de Iquique, donde estaba la fosa común con los muertos de la Plaza Montt o de la escuela Santa María fue eliminado, maquinarias realizaron movimientos de tierras para borrar su existencia. La pobreza y la escasez de suelo hicieron surgir allí viviendas precarias que con el paso del tiempo se transformaría en otro barrio de la ciudad, llamado irónicamente "Progreso". Aunque la instalación del agua potable y el alcantarillado acusaron los vestigios del antiguo cementerio, todo quedó sepultado como un secreto. Y la fosa común desapareció junto al camposanto, el destino de los cuerpos sigue siendo una polémica hasta hoy.

Vovelle señala que el tema de la muerte ofrece una cantera inmensa para la historiografía, que la muerte está asociada al silencio, pero es a la vez prolífica, porque la muerte es temida, ella es la última fuente de los que no dejaron registro escrito de su paso por el mundo. Este autor nos recuerda que "la muerte está en el centro de toda aventura humana" (2000:39).

Para el centenario de la masacre obrera, el municipio de la ciudad construyó una réplica del mausoleo de madera del cementerio $\mathrm{N}^{\circ} 2$ de 1911. Fue instalada esta réplica a la entrada del cementerio $\mathrm{N}^{\mathrm{o}} 1$, quizás como una tardía reparación (Figura 3).

El diario La Tercera del 4 de marzo de 2007, p. 30, incluía un reportaje donde se entrevista al trabajador del cementerio $\mathrm{N}^{\circ} 3$, Daniel Mancilla,

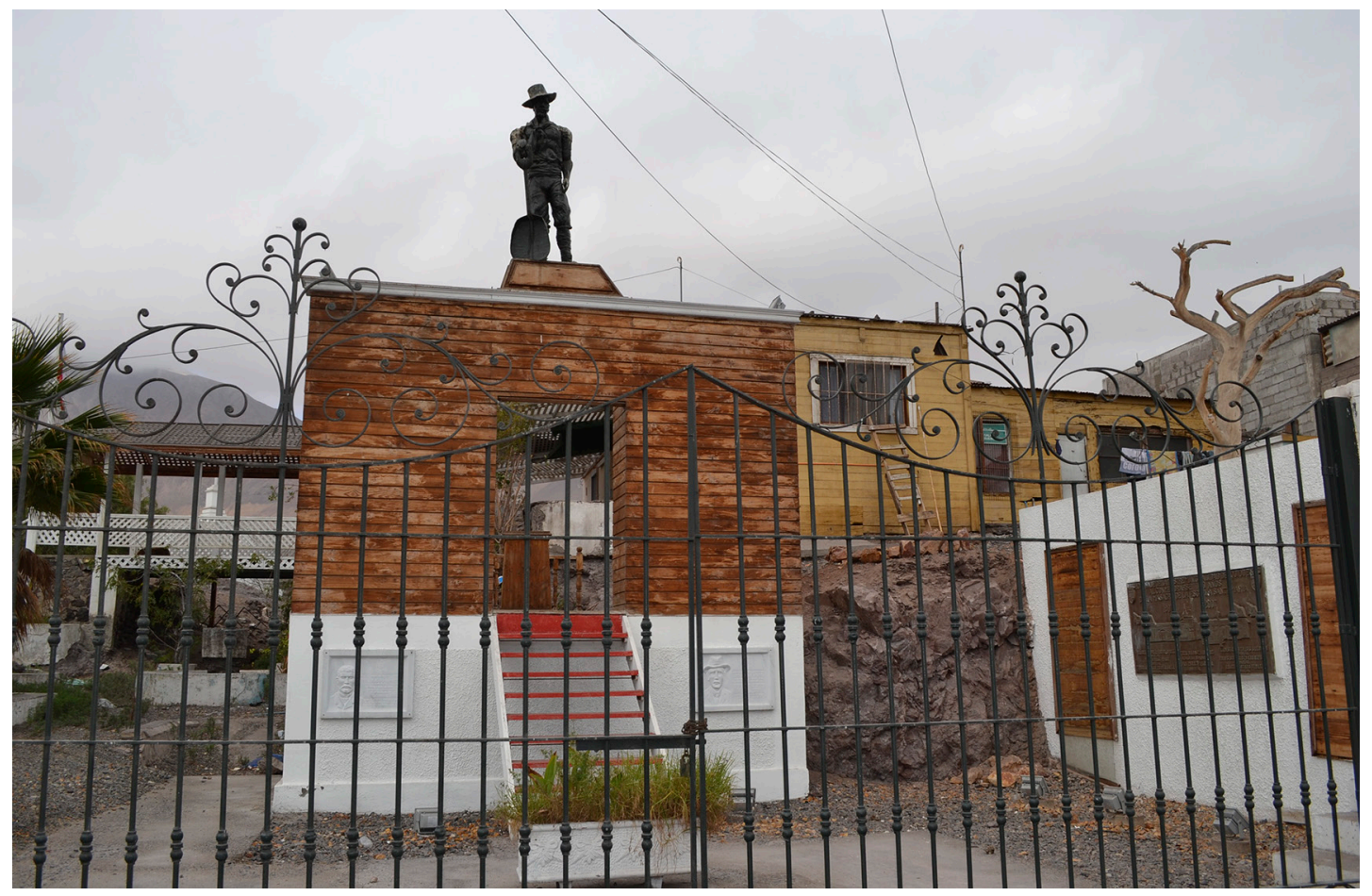

Figura 3. Réplica del Mausoleo de los Mártires de la Plaza Montt. Fuente: Archivo fotográfico del autor. 
quien relata que le correspondió trasladar -a fines de los años 1960- los restos de los cuerpos ubicados en la fosa del cementerio $\mathrm{N}^{\circ} 2$ al $\mathrm{N}^{\circ} 3$. Trabajaron cerca de cuatro meses y trasladaron cerca de mil cuerpos a otra fosa común. La opinión pública solicitaba con la emoción del centenario volver a exhumar los restos, incluida la Central Única de Trabajadores de la provincia. Mientras el filósofo Víctor Farías anunciaba su libro: Santa María: la realidad de un mito, por la editorial Maye, donde señala como responsables a los dirigentes de la huelga y reivindica el orden social.

\section{Conclusiones}

Un poema de Pablo Neruda denominado Los Muertos de la Plaza², publicado el 28 de enero de 1948 en Santiago, recoge el drama de las masacres obreras o campesinas en Chile. En dicho poema hace referencia a los muertos en Iquique, en la Plaza Montt. Sin embargo, será la Cantata de la Escuela Santa María de Iquique, compuesta en 1969 por el músico iquiqueño Luis Advis Vitaglic, que llevará a este suceso a la conciencia nacional y al conocimiento internacional inmortalizando aquellos imaginarios (Figura 4).

Dicho eso, y a pesar de la catastrófica masacre que fueron víctimas los obreros salitreros en la escuela Santa María en 1907, son precisamente aquellos imaginarios que inmortalizan los rostros de estos sujetos históricos. Los relatos de los testigos y protagonistas del suceso, transcurriendo de relato en relato, han construido un discurso social, produciendo imaginarios que cristalizan rostros de rabia, pena, desazón y lucha, en donde el imposible moral de Levinas se hace experiencia inmortalizada en los habitantes de Iquique y la Región de Tarapacá. Y aunque el poderío violento y estructural, en el ejercicio de negación de su alteridad de clase, hizo crujir el centro iquiqueño con miles de disparos, y el rostro del general Silva Renard como símbolo de autoridad, no permitió la extinción de la imagen obrera de los 18 peniques y toda la sociedad pampina.

En lo que respecta al aspecto cuantitativo de los rostros sostenidos en la memoria colectiva y los imaginarios históricos, es un hecho que no se puede dar una cifra única, pero lo más destacable es tal como manifiesta Mario Bahamonde: la muerte no es una estadística, y mucho menos esta masacre. Esta masacre es un dato duramente cualitativo e intersubjetivo, donde se expresa la violencia estructural y la alteridad de clase, en contra de la reivindicación popular, el alzamiento organizado y la solidaridad por la justicia, lo que concluye marcando un periodo político, histórico y social de la región y el país.

En definitiva, la pregunta es ¿qué nos quedó después de este episodio trágico de la historia de Chile? Nos quedan los imaginarios, sus respectivos rostros, su legado, su honor y rabia, los discursos plasmados en múltiples relatos, como también su

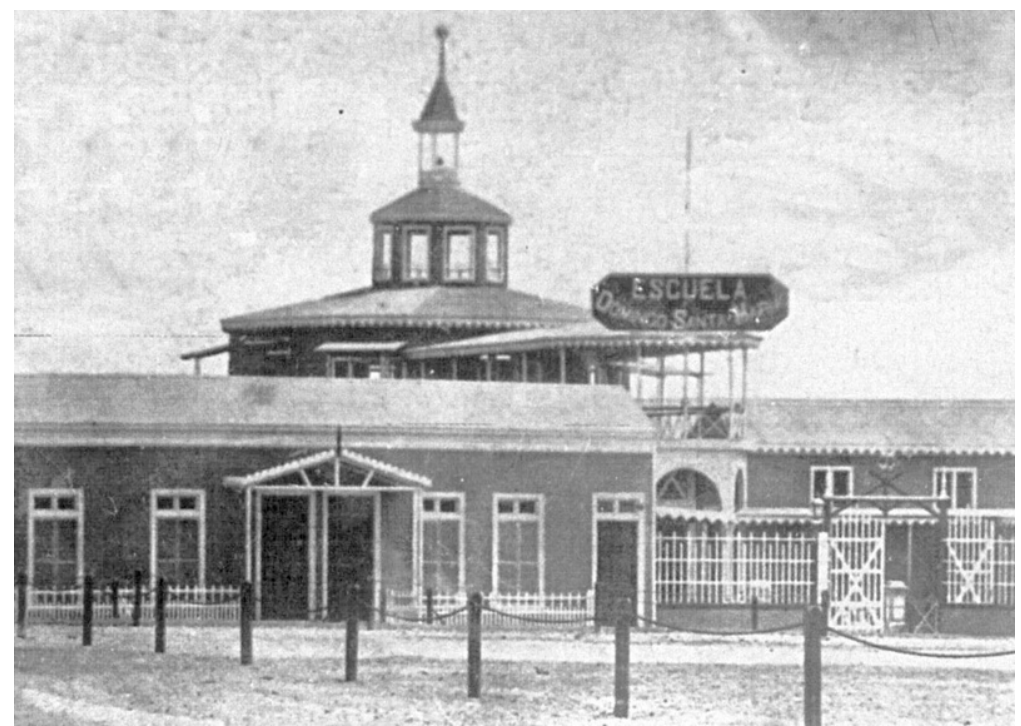

Figura 4. Escuela Santa María de Iquique. Fuente: Diario Iquique. 2011. 
clara añoranza por una sociedad menos injusta, violentada y asesinada.

Y más allá de los mausoleos, el desaparecido Cementerio II, y el contenido intersubjetivo e ideacional del recuerdo de la lucha dada por los obreros de 1907, nos queda mucho por rescatar de sus prácticas, para nuestras prácticas, es decir, no solo valorar el hecho martirizado de haber dado sus vidas dignamente, sino que también inmortalizar y significar sus prácticas que dan origen a aquella organización masiva y cohesionada que permitió una caravana desértica de esperanza: elementos muchas veces olvidados en la praxis política, social, sindical y cultural, no solo del norte, sino que de este lado del mundo que aún mantiene estructuras de poder que recurren a la violencia de alteridad de clase para la represión de ideas y acciones organizadas en virtud de una construcción distinta de sociedad.

\section{Agradecimientos}

A Sergio González Miranda, por permitirme el acceso al Archivo de testimonios de Hombres y Mujeres de la Pampa (AHMP) y por sus comentarios al borrador, como a los evaluadores de este manuscrito.

\section{Referencias Citadas}

Alfaro, C.

1936 Reseña histórica de la provincia de Tarapacá. Semana Tarapaqueña, Iquique.

Aries, P.

1999 El hombre ante la muerte. Editorial Taurus: Madrid. Artaza, P.

2006 Movimiento social y politización popular en Tarapacá, 1900-1912. Editorial Escaparate, Concepción.

Bahamonde, $\mathrm{M}$.

1973 Pampinos y salitreros. Editorial Quimantú, Santiago de Chile.

Bravo-Elizondo, P.

2007 Santa María de Iquique 1907: documentos para su historia. Ediciones Campvs, Iquique.

Devés, E.

1988 Los que van a morir te saludan. Historia de una masacre. Escuela Santa María de Iquique, 1907. Ediciones Documentas, Nuestra América Ediciones, América Latina Libros, Santiago de Chile.

Fernández, M.

1988 Proletariado y salitre en Chile, 1890-1910. Monografías de Nueva Historia, Londres.

Figueroa, C.

2011 Cartografiando el progreso: espacios de civilización y barbarie en la provincia de Tarapacá (1825-1884). Scripta Nova Revista Electrónica de Geografía y Ciencias Sociales, 15 (370), rescatado en: www.ub.edu/geocrit/sn/sn-370.htm

Galtung, J.

1995 Investigaciones teóricas. Editorial Tecnos, Madrid.

González, S.

1995 Cochabambinos de habla quechua en las salitreras de Tarapacá (1880-1930). Chungará Revista de Antropología Chilena, 27 (2): 135-151.

González, S. et al.

1998 Poemario popular de Tarapacá 1899-1910. Ediciones UNAP, DIBAM, LOM, Santiago de Chile.

González, S.

2002 Hombres y mujeres de la Pampa. Lom Editores, Santiago de Chile.

González, S.

2006 La presencia indígena en el enclave salitrero de Tarapacá: una reflexión en torno a la fiesta de La Tirana.
Chungara Revista de Antropología Chilena, 38 (1): 35-49.

González, S.

2007 Ofrenda a una masacre. Claves e indicios históricos de la emancipación pampina de 1907. Editorial LOM, Santiago de Chile.

Levinas, E.

2012 Totalidad e infinito. Ediciones Sígueme, Salamanca.

Levinas, E.

2014 Alteridad y trascendencia. Ediciones Arena Libros, Madrid.

Marín, L.

190821 de diciembre. Compendio y relación exacta de la huelga de pampinos desde su principio hasta su terminación. 15 de febrero de 1908, s/p, sin editorial, Iquique.

Morín, E.

2011 El hombre y la muerte. Editorial Kairós, Barcelona.

Navarro, O.

2008 El "rostro" del otro: una lectura de la ética de la alteridad de Emmanuel Levinas. Contrastes Revista Internacional de Filosofía, (13): 177-194.

Núñez, L.

2004 La Tirana del tamarugal. Ediciones Universidad Católica del Norte, Santiago de Chile.

Pinto, J.

1998 Rebeldes pampinos. Los rostros de la violencia popular en las oficinas salitreras (1870-1900). En Trabajos y rebeldías en la pampa salitrera. Editorial USACH, Santiago de Chile.

Pizarro, C.

1986 La huelga obrera en Chile. Editorial Sur, Santiago de Chile.

Van Kessel, J.

1987 Lucero del desierto. Ediciones CIREN, Iquique.

Vovelle, M.

2000 Historia de la muerte. En Cuadernos de Historia, (18): $37-49$.

Zolezzi, M.

2002 El General represor de la "huelga de los 18 peniques". Tarapacá, diciembre de 1907. Editorial Campvs, Iquique. 


\section{Fuentes}

\section{Periódicos}

Periódico El Nacional (1907). En Sección Periódico Biblioteca Nacional.

Periódico El Proletario (1907). En Sección Periódico Biblioteca Nacional.

Periódico El Pueblo (1908). En Sección Periódico Biblioteca Nacional.

Periódico El Pueblo Obrero (1907). En Sección Periódico Biblioteca Nacional.
Periódico El Trabajo (1907). En Sección Periódico Biblioteca Nacional.

Periódico El Tarapacá (1959). En Sección Periódico Biblioteca Nacional.

Periódico El Tarapacá (1951). En Sección Periódico Biblioteca Nacional.

Periódico El Socialista (1917). En Sección Periódico Biblioteca Nacional.

Periódico La Tercera (2007). En Sección Periódico Biblioteca Nacional.

\section{Notas}

1 Este registro será utilizado para el total de las entrevistas referenciadas en el texto. Respecto de este archivo ver: González, Sergio y Pablo Artaza "Cateando la palabra. La construcción de nuevos archivos sobre la sociedad del salitre", en Revista Diálogo Andino N 46, pp. 55-70.
2 (Fragmento) "Yo no vengo a llorar aquí donde cayeron: vengo a vosotros, acudo a los que viven. Acudo a ti y a mí y en tu pecho golpeó. Cayeron otros antes. ¿Recuerdas? Sí, recuerda" (Pablo Neruda). 
